\title{
THE ABUNDANCE AND AGE DISTRIBUTION OF 500 F STARS IN THE SOLAR NEIGHBOURHOOD
}

\author{
R. E. S. CLEGG and R. A. BELL \\ University of Maryland, U.S.A.
}

A short account of the paper published in Monthly Notices Roy. Astron. Soc. 163, 13, 1973 was presented by R. A. Bell. 